only mild COVID-19 symptoms confirmed the effectiveness of both vaccines to prevent severe disease and mortality. ${ }^{7,8}$

Our study had some limitations including the small sample size, the limited number of HCP who participated in a vaccination serological study after vaccination, and the possibility of misclassification bias from using epidemiology data to classified healthcare-associated SARS-CoV-2 transmission.

Additional studies to evaluate the viral transmission dynamic for the delta variant and its impact on healthcare-associated transmission among HCP who have completed different types of COVID-19 vaccine, as well as a longitudinal data regarding anti-S-RBD-Ab IgG among HCP, will provide insight into better protection of healthcare-associated transmission of COVID-19 among HCP.

\section{Acknowledgments.}

Financial support. No financial support was provided relevant to this article.

Conflicts of interest. All authors report no conflicts of interest relevant to this article.

Supplementary material. To view supplementary material for this article, please visit https://doi.org/10.1017/ice.2021.365

\section{References}

1. Nguyen LH, Drew DA, Graham MS, et al. Risk of COVID-19 among frontline healthcare workers and the general community: a prospective cohort study. Lancet Public Health 2020;5:475-483.

2. Chirico F, Nucera G, Magnavita N. COVID-19: protecting healthcare workers is a priority. Infect Control Hosp Epidemiol 2020;41:1117.

3. Corona virus diseases. Department of Disease Control website. https://ddc. moph.go.th/viralpneumonia/eng/index.php. Accessed July 4, 2021.

4. Corona virus information. McGill website. https://www.mcgill.ca/coronavirus/ health-guidelines/potential-covid-19-exposure-what-do. Accessed July 4, 2021.

5. Coronavirus diseases 2019 (COVID-19) treatment guidelines. National Institutes of Health website. https://www.covid19treatmentguidelines.nih. gov/. Accessed July 4, 2021.

6. Amanant E, Stadlbauer D, Strohmeier S, et al. A serological assay to detect SARS-CoV-2 seroconversion in humans. Nat Med 2020;26: 1033-1036.

7. Palacios R, Patiño EG, de Oliveira Piorelli R, et al. Double-blind, randomized, placebo-controlled phase III clinical trial to evaluate the efficacy and safety of treating healthcare professionals with the adsorbed COVID-19 (inactivated) vaccine manufactured by Sinovac_-PROFISCOV: a structured summary of a study protocol for a randomised controlled trial. Trials 2020;21:853.

8. Knoll MD, Wonodi C. Oxford-AstraZeneca COVID-19 vaccine efficacy. Lancet 2021;397:72-74.

\title{
Transmission of severe acute respiratory coronavirus virus 2 (SARS-CoV-2) among health careworkers (HCWs) during three waves of the coronavirus disease 2019 (COVID-19) pandemic in Germany: Results of an anonymous survey
}

\author{
Prof. Dr. med. Sebastian Schulz-Stübner ${ }^{1}$ and Elke Pielert ${ }^{2}$ \\ ${ }^{1}$ German Consulting Center for Infection Prevention and Control [Deutsches Beratungszentrum für Hygiene (BZH GmbH)], Freiburg, Germany and ${ }^{2} \mathrm{Krankenhaus}$ \\ St. Elisabeth und St. Barbara Halle (Saale) GmbH, Halle (Saale), Germany
}

To the Editor-In an editorial in the Journal of the American Medical Association (JAMA), Gohil and Huang postulated the following: "Healthcare personnel (HCP) have absorbed substantial risks of acquiring coronavirus disease 2019 (COVID-19) due to their care of patients with COVID-19 infection throughout the pandemic. Nevertheless, because of robust health care infection prevention and control practices and policies that prevent patient-to-HCP transmission, it is possible that the greatest risk of COVID-19 transmission to HCP comes from exposure in their communities and, secondarily, between essential workers."

To learn more about the transmission of severe acute respiratory coronavirus virus 2 (SARS-CoV-2) among healthcare workers (HCWs), we conducted an anonymous survey that was distributed by mass e-mail through interested infection control practitioners to all employees in their respective institution. The survey sheets

Author for correspondence: Prof. Dr. Sebastian Schulz-Stübner, E-mail: Schulzstuebner@bzh-freiburg.de

Cite this article: Schulz-Stübner PDS and Pielert E. (2022). Transmission of severe acute respiratory coronavirus virus 2 (SARS-CoV-2) among health careworkers (HCWs) during three waves of the coronavirus disease 2019 (COVID-19) pandemic in Germany: Results of an anonymous survey. Infection Control \& Hospital Epidemiology, 43: 1742-1744, https://doi.org/10.1017/ice.2021.359 were printed out and sent without sender information by mail to a central collecting address to guarantee that no backward data tracking was possible. No personal identifying data were collected, in accordance with German General Data Protection Regulation (GDPR). Because this was not a human-subject study, no ethics committee review was needed.

Because of the completely anonymous data collection, we do not know how many surveys were distributed. In total, 116 survey sheets were returned, and 1 was excluded because of implausible data. Table 1 shows the detailed results which clearly identify the 3 COVID-19 waves in Germany during the periods evaluated in the study. In total, 17 cases with mild or no symptoms and short duration were breakthrough infections during the third wave; however, only 2 were fully vaccinated according to the current definition ( $>14$ days after the second shot of the respective vaccine).

Overall, $14 \%$ of the 115 cases were attributed to private contacts, $8 \%$ were undetermined and $78 \%$ were attributed to professional contacts. In addition, 54 (60\%) of those 90 cases were related to unprotected contact of $>15$ minutes to undiagnosed patients or colleagues and $18(20 \%)$ to aerosol-generating procedures (AGPs). Among those 18 AGP cases, free-text comments indicated 3 cases involving endotracheal intubation and 1 case 
Table 1. Results from the anonymous questionnaire from 115 healthcare workers (HCWs) with confirmed SARS-CoV-2 infection between January 2020 and April 2021

\begin{tabular}{|c|}
\hline Demographics \\
\hline $\begin{array}{l}\text { - } n=115 \\
\text { - } 90 \text { female } \\
\text { - } 21 \text { male } \\
\text { - } 4 \text { missing data } \\
\text { - Average age: } 44 \text { years } \\
\text { - Primary care hospital: } 70 \% \\
\text { - Secondary and tertiary-care hospitals: } 30 \%\end{array}$ \\
\hline Distribution of professionals \\
\hline $\begin{array}{l}\text { - } 70 \text { nurses }(61 \%) \\
\text { - } 12 \text { physicians }(11 \%) \\
\text { - } 15 \text { medical technicians }(13 \%) \\
\text { - } 7 \text { service staff }(6 \%) \\
\text { o } 3 \text { housekeeping } \\
\text { o } 4 \text { kitchen } \\
\text { - } 5 \text { administrative staff }(4 \%) \\
\text { - } 2 \text { trainees }(2 \%) \\
\text { - } 4 \text { missing data }(3 \%) \\
\end{array}$ \\
\hline Period of infection \\
\hline $\begin{array}{l}\text { - January-April } 2020 \text { (first wave): } 20 \text { (17\%) } \\
\text { - May-August } 2020 \text { (summer pause): } 0 \\
\text { - September-December } 2020 \text { (second wave): } 62 \text { (54\%) } \\
\text { - January-April } 2021 \text { (third wave): } 32(28 \%) \\
\text { - Missing data: } 1(1 \%)\end{array}$ \\
\hline Breakthrough infections in vaccinated HCWs \\
\hline $\begin{array}{l}\text { - } \mathrm{n}=17 \\
015 \text { with } 1 \text { shot }(8 \times \text { Comirnaty, } 7 \times \text { Vaxzevria) } \\
\circ 2 \text { with } 2 \text { shots (Comirnaty) }\end{array}$ \\
\hline Source of infection \\
\hline $\begin{array}{l}\text { - Undetermined: } 9 \text { ( } 8 \%) \\
\text { - Private contact: } 16(14 \%) \\
\text { - Professional contact } 90 \text { ( } 78 \%) \\
\square \text { Unprotected contact > } 30 \text { minutes: } 35(39 \%) \\
\square \text { Unprotected contact > } 15 \text { minutes: } 19(21 \%) \\
\square \text { Aerosol-generating procedure: } 18(20 \%) \\
\square \text { Missing data: } 18(20 \%)\end{array}$ \\
\hline Type of mask worn routinely (>1 type possible) \\
\hline $\begin{array}{l}\text { - Medical mask: } 30(26 \%) \\
\text { - FFP-2: } 72(63 \%) \\
\text { - KN95: } 20(17 \% \\
\text { - FFP-3: } 12(10 \%) \\
\text { - Others: } 1(1 \%)\end{array}$ \\
\hline Air conditioning system in place \\
\hline $\begin{array}{l}\text { - Yes: } 30(26 \%) \\
\text { - No: } 81(71 \%) \\
\text { - Missing data: } 4(3 \%)\end{array}$ \\
\hline Severity of illness \\
\hline $\begin{array}{l}\text { - Mild: } 108(94 \%) \\
\text { - Severe (with pneumonia): } 7(6 \%) \\
\text { o } 2 \text { with supplemental oxygen }\end{array}$ \\
\hline Duration of symptoms \\
\hline $\begin{array}{l}\text { - } 10 \text { days: } 64(56 \%) \\
\text { - } 7-10 \text { days: } 14(12 \%) \\
\text { - } 4-6 \text { days: } 22(19 \%) \\
\text { - } 1-3 \text { days: } 10(9 \%) \\
\text { - Missing data: } 5(4 \%)\end{array}$ \\
\hline
\end{tabular}

Table 1. (Continued)

\begin{tabular}{l}
\hline Demographics \\
\hline Type of symptoms \\
\hline - Fever: $31(27 \%)$ \\
- Sour throat: $48(42 \%)$ \\
- Fatigue: $103(89 \%)$ \\
- Headache: $78(68 \%)$ \\
- Muscle ache: $62(54 \%)$ \\
- Chest pain: $33(29 \%)$ \\
- Cough: $60(52 \%)$ \\
- Nausea: $14(12 \%)$ \\
- Vomiting: $7(6 \%)$ \\
- Diarrhea: $21(18 \%)$ \\
- Pneumonia: $7(6 \%)$ \\
\hline Secondary cases among household contacts \\
\hline - 109 of $284(38 \%)$ \\
\hline Which prevention strategy is feasible in your institution \\
\hline - Maintaining physical distance: $29(25 \%)$ \\
- Frequent window opening: 69 ( $60 \%)$ \\
- Wand hygiene: 109 (95\%) \\
\hline
\end{tabular}

Note. FFP, filtering face piece; KN, Chinese standard.

of mask ventilation during cardiopulmonary resuscitation, 4 cases with difficulties during inhalational therapy or noninvasive ventilation, and 3 cases with extensive coughing during mouth care in uncooperative patients.

Our survey was limited by the number of responses and potential response and recall bias; however, it shows some potentially interesting facts for further focused research and risk assessment.

Unprotected contact with either undiagnosed patients or colleagues is described in the literature as relevant source, ${ }^{2,3}$ and it seems to play an important role in SARS-CoV-2 infections among HCWs in our cohort as well with involvement of not only medical frontline HCW s but also support and administrative staff. Interestingly during the first wave and during summer, the incidence per 100,000 population was less than that in the general public for HCWs in Germany. ${ }^{4}$ HCW infections related to private contacts outside of the hospital showed an equal distribution in all 3 waves in our cohort.

In this context, general preventive measures (keeping distance, wearing of masks, hand hygiene and frequent window opening) are important, but keeping distance seems to be especially problematic in the healthcare setting. Distancing was described as feasible by only $25 \%$ of survey respondents.

The secondary attack rate among household members in our cohort was $38 \%$, with wide individual ranges, for example, from 4 in 4 to 2 in 7 , from 12 in 15 or 0 in 16 , but no significant differences between the 3 periods with dominance of different SARS CoV 2-variants. There were also no differences in secondary attack rates in those with breakthrough infections after only 1 dose of the Comirnaty vaccine or Vaxzevria vaccine. Thus, those early breakthrough infections have a clinically relevant transmission potential. As described in the literature, ${ }^{5}$ breakthrough infection in fully vaccinated HCW were rare in our cohort.

These secondary attack rates, a missing protective effect of air conditioning systems in place, and the fact that mostly high-grade face masks (FFP-2, FFP-3, and KN95) were used during routine 
care raises questions about the relevance of far distance airborne transmission in most clinical settings. A near-distance transmission mode is more likely the dominant mode of transmission. This could be the case even for AGPs, given the high number of close distance and direct contacts described during the specific AGPs performed by our cohort that resulted in transmission despite use of FFP-2 or FFP-3 masks. Our assumptions are limited by the fact that no data about fit testing, the use of face shields or goggles, and other personal protective equipment for contact precautions were collected. However numerous personal observations of the removal procedure of FFP-2 mask confirm the potential of hand contamination, with the mask becoming a fomite as shown by fluorescein and bacteriophage markers in the literature. ${ }^{6}$ This is especially likely after stressful events like resuscitation and emergency airway management, as demonstrated in simulation studies of donning and doffing of personal protective equipment. ${ }^{7}$ Lentz et $\mathrm{al}^{8}$ showed a protective effect of respirator use during APGs and lower odds ratios of infections in intensive care units, dedicated COVID-19 units, and the presence of personal protective equipment observers in a global case-control study.

In summary, unprotected contacts off work and with undiagnosed patients or fellow HCWs during work seem to be a major driver of SARS-CoV-2 infections among HCWs, making general protective measures a necessity at least until full vaccination status is reached.

Acknowledgments.

Financial support. This work was funded by institutional funds only.
Conflicts of interest. All authors report no conflicts of interest relevant to this article.

\section{References}

1. Gohil SK, Huang SS. Community COVID-19 incidence and health care personnel COVID-19 seroprevalence. JAMA Network Open 2021;4(3):e211575.

2. Schneider S, Piening B, Nouri-Pasovsky PA, Krüger AC, Gastmeier P, Aghdassi SJS. SARS-coronavirus-2 cases in HCWs may not regularly originate from patient care: lessons from a university hospital on the underestimated risk of healthcare worker to healthcare worker transmission. Antimicrob Resist Infect Control 2020;9:192.

3. Brandt MP, Jäger W, Epple S, Haferkamp A, Schräder A. SARS-CoV-2 outbreak in medical employees in a large urologic department: spread, containment and outcome. Am J Infect Control 2021;49:674-677.

4. Pfenninger EG, Christ $\mathrm{P}$, Neumüller $\mathrm{M}$, et al. Beurteilung des Infektionsrisikos durch SARS-CoV-2 für medizinisches personal-erkenntnisse aus der Praxis. Bundesgesundheitsbl 2021;64:304-313.

5. Tang L, Hijano DR, Gaur AH, et al. Asymptomatic and symptomatic SARS $\mathrm{CoV} 2$ infections after BNT162b2 vaccination in a routinely screened workforce. JAMA 2021;326:2500-2502.

6. Brady TM, Strauch AL, Almaguer CM, et al. Transfer of bacteriophage MS2 and fluorescein from $\mathrm{N} 95$ filtering facepiece respirators to hands: measuring fomite potential. J Occup Environ Hyg 2017;14:898-906.

7. Díaz-Guio DA, Ricardo-Zapata A, Ospina-Velez J, Gómez-Candamil G, Mora-Martinez S, Rodriguez-Morales AJ. Cognitive load and performance of healthcare professionals in donning and doffing PPE before and after a simulation-based educational intervention and its implications during the COVID-19 pandemic for biosafety. Infez Med 2020;28 suppl 1:111-117.

8. Lentz RJ, Colt $\mathrm{H}$, Chen $\mathrm{H}$, et al. Assessing coronavirus disease 2019 (COVID-19) transmission to healthcare personnel: the global AVT-HCP case control study. Infect Control Hosp Epidemiol 2021;42:381-387.

\title{
Postacute coronavirus disease 2019 (COVID-19) syndrome in maxillofacial surgeons after initial infection: A Brazilian experience
}

\author{
Lucas Alves da Mota Santana DDS, MSC ${ }^{1}$ (1), Marcos Antônio Lima dos Santos DDS, MSC ${ }^{1}$, \\ Hélio Igor Melo de Albuquerque DDS, MSC ${ }^{1}$, Eduardo Morato de Oliveira DDS, MSC ${ }^{2}$, \\ Lucyene Miguita Luiz DDS, MSC, $\mathrm{PhD}^{3}$, Wilton Mitsunari Takeshita DDS, MSC, $\mathrm{PhD}^{1}$ and \\ Liane Maciel de Almeida Souza DDS, MSC, $\mathrm{PhD}^{1}$ \\ ${ }^{1}$ Department of Dentistry, Universidade Federal de Sergipe, Aracaju, Sergipe, Brazil, ${ }^{2}$ Oral Surgery and Pathology, Department School of Dentistry, Universidade \\ Federal de Minas Gerais, Belo Horizonte, Minas Gerais, Brazil and ${ }^{3}$ Department of Pathology, Institute of Biological Science, Universidade Federal de Minas \\ Gerais, Belo Horizonte, Minas Gerais, Brazil
}

To the Editor - The coronavirus disease 2019 (COVID-19) pandemic has been major sanitary crisis of recent times. Its pathogenesis is complex and systemic manifestations are the most varied. ${ }^{1}$ In addition to serious cases of hospitalization, persistent symptoms have been observed in patients that impact on rehabilitation and quality of life. ${ }^{2}$ This clinical condition is recognized as a postacute

\footnotetext{
Author for correspondence: Dr Lucas Alves da Mota Santana, E-mail: lucassantana. pat@gmail.com

Cite this article: Santana LAM, et al. (2022). Postacute coronavirus disease 2019 (COVID-19) syndrome in maxillofacial surgeons after initial infection: A Brazilian experience. Infection Control \& Hospital Epidemiology, 43: 1744-1746, https://doi.org/ $10.1017 /$ ice. 2021.401
}

COVID-19 syndrome that affects different severe acute respiratory coronavirus virus 2 (SARS-CoV-2)-positive patients. ${ }^{2,3}$

By acting directly with the oral cavity and subsequent exposure to aerosol and saliva, dentists are at risk for infection by novel coronavirus and, consequently, can also develop sequelae. ${ }^{4}$ Thus, we report a case series of post-acute COVID-19 syndrome in maxillofacial surgeons of a Brazilian public center and highlight the need for clinical follow-up of these professionals.

Between April and June 2020, 20 maxillofacial surgeons in Sergipe, Brazil, worked during the first wave of COVID-19 performing high complexity surgeries and, unfortunately, most of them were infected (15 of 20,75\%). In addition, 4 individuals tested positive for SARS-CoV-2 in subsequent months (2-5 months) (Table 1$)$. 